\title{
In vitro examination of the antimicrobial activity of a potentially probiotic Lactobacillus acidophilus strain against Escherichia coli, Staphylococcus aureus and Salmonella sp.
}

\author{
Zapryana Denkova ${ }^{1}$, Velichka Yanakieva ${ }^{1}$, Bogdan Goranov $^{1}$, Teodora Tomova ${ }^{1}$, Rositsa Denkova-Kostova ${ }^{2, *}$, \\ Nadia Oulahal $^{3}$, Georgi Kostov ${ }^{4}$, and Pascal Degraeve ${ }^{3}$ \\ ${ }^{1}$ Department of Microbiology, Technological Faculty, University of Food Technologies, Plovdiv, Bulgaria \\ ${ }^{2}$ Department of Biochemistry and Molecular Biology, Technological Faculty, University of Food Technologies, Plovdiv, Bulgaria \\ ${ }^{3}$ BioDyMIA (Bioengineering and Microbial Dynamics at Food Interfaces) Université Lyon 1- ISARA Lyon Joined Research Unit, \\ Université de Lyon, Bourg en Bresse, France \\ ${ }^{4}$ Department of Wine and Beer Technology, Technological Faculty, University of Food Technologies, Plovdiv, Bulgaria
}

\begin{abstract}
An interesting property for many probiotic strains is to exhibit antimicrobial activity against pathogenic microorganisms. Therefore, the antimicrobial activity of the potentially probiotic strain Lactobacillus acidophilus L12 against Escherichia coli, Staphylococcus aureus and Salmonella sp. was examined in vitro through co-culturing of Lactobacillus acidophilus L12 with each of the pathogenic strains for $72 \mathrm{~h}$. When cultured individually, all strains reached a final population always exceeding $10^{12} \mathrm{cfu} / \mathrm{mL}$. When co-cultured with each of the pathogenic strains Lactobacillus acidophilus L12 population always exceeded $10^{12} \mathrm{cfu} / \mathrm{mL}$, while the bacterial population of the pathogenic strains was reduced in a strain-specific manner. Lactobacillus acidophilus L12 demonstrated the highest inhibitory activity against the two Staphylococcus aureus strains, followed by the two E. coli strains, and the two Salmonella sp. strains tested. The kinetics of the co-culturing process of Lactobacillus acidophilus L12 with each of the test pathogenic strains was modelled using the logistic curve model. The obtained results show the strong antagonistic activity of the potentially probiotic strain Lactobacillus acidophilus L12, thus making it a promising candidate for inclusion in the composition of probiotic preparations and functional probiotic foods.
\end{abstract}

\section{Introduction}

Only lactobacilli strains that have certain properties can be included in the composition of probiotics and probiotic foods [1]: (i) to be part of the natural microflora in humans and animals; (ii) to have the ability to adhere to epithelial cells or cell lines; (iii) to survive in the conditions of the stomach and intestines, i.e. to survive in the conditions of acidic $\mathrm{pH}$ in the stomach and to be resistant to the action of bile juice; (iv) to reproduce in the gastrointestinal tract by assimilating mainly the substrate and to suppress and expel from the biological niche pathogenic and toxigenic microorganisms; (v) to allow industrial cultivation, inclusion in gel matrices (encapsulation) and to retain their activity following processes such as freeze-drying, as well as in the finished products; (vi) to have antimicrobial activity against opportunistic, carcinogenic and pathogenic microorganisms, which is associated with inactivation of their enzyme systems, overcoming their adhesion, inhibiting their growth and/or expulsion from the biological niche, resulting in normalization of the gastrointestinal microflora; (vii) to produce antimicrobial substances; (viii) to modulate the immune response; (ix) to be safe for clinical and nutritional use.

Thus, an interesting property for probiotic strains is to exhibit antimicrobial activity against pathogenic microorganisms so that they can play their protagonistic role in the human gastrointestinal tract and reduce the number of harmful bacteria and restore the balance of the gastrointestinal microflora [2, 3].

Lactobacillus acidophilus strains have already been reported to adhere to the surface of intestinal epithelial cells. However, this adhesion is strictly specific to each individual [4]. Adhesion is performed with lectin-like proteins in the surface protein layer of $L b$. acidophilus. Besides, several Lactobacillus acidophilus strains produce bacteriocins such as lactacin $\mathrm{B}$, lactacin $\mathrm{F}$ and acidocin. The bacteriocin gasericin A was isolated from Lactobacillus gasseri. It shows high inhibitory activity against a wide range of food pathogenic bacteria such as Listeria monocytogenes, Bacillus cereus and Staphylococcus aureus. Gasericin A is a highly hydrophobic bacteriocin. This is the first cyclic bacteriocin isolated from the group of lactic acid bacteria $[5,6]$.

\footnotetext{
* Corresponding author: rositsa denkova@mail.bg
} 
The aim of the present study was to determine the in vitro inhibitory activity of a potential probiotic strain of Lactobacillus acidophilus against the growth of the pathogenic bacterial strains Escherichia coli ATCC 25922, Escherichia coli ATCC 8739, Staphylococcus aureus ATCC 25293, S. aureus ATCC 6538P, Salmonella enteritidis ATCC 13076, and Staphylococcus abony NTCC 6017, by co-culturing the Lactobacillus acidophilus L12 strain with each of these pathogenic bacterial strains.

\section{Materials and methods}

\subsection{Microorganisms}

The studies in the present work were performed with Lactobacillus acidophilus L12 isolated from the rose blossom of Rosa damascena Mill and identified by the authors of the present manuscript using biochemical (API $50 \mathrm{CHL}$ ) and molecular-genetic (sequencing of the $16 \mathrm{~S}$ rDNA) methods (data not published). The strain is stored at $4 \pm 2{ }^{\circ} \mathrm{C}$ or frozen.

The antagonistic activity against 6 foodborne pathogenic bacterial strains of Lactobacillus acidophilus L12 strain was investigated: Escherichia coli ATCC 25922, Escherichia coli ATCC 8739, Staphylococcus aureus ATCC 25293, Staphylococcus aureus ATCC 6538P, Staphylococcus enteritidis ATCC 13076, Staphylococcus abony NTCC 6017.

\subsection{Media}

\subsubsection{MRS broth}

Composition (g/l): peptone from casein - 10; yeast extract - 4; meat extract - 8; glucose $-20 ; \mathrm{K}_{2} \mathrm{HPO}_{4}-2$; sodium acetate -5 ; diammonium citrate $-2 ; \mathrm{MgSO}_{4}-$ $0.2 ; \mathrm{MnSO}_{4}-0.04 ;$ Tween $80-1 \mathrm{ml} / 1 ; \mathrm{pH}=6.5$. Sterilization -15 minutes at $118^{\circ} \mathrm{C}$.

\subsubsection{LAPTg10 broth}

Composition (g/l): peptone - 15; yeast extract - 10; tryptone - 10; glucose - 10; Tween $80-1 \mathrm{ml} / \mathrm{l}$. $\mathrm{pH}=6.6-$ 6.8. Sterilization $-20 \mathrm{~min}$ at $121^{\circ} \mathrm{C}$.

\subsubsection{LAPTg10 agar}

Composition $(\mathrm{g} / \mathrm{l})$ : peptone -15 ; yeast extract -10 ; tryptone - 10; glucose - 10; Tween $80-1 \mathrm{ml} / \mathrm{l}$, agar -15 . $\mathrm{pH}=6.6-6.8$. Sterilization $-20 \mathrm{~min}$ at $121^{\circ} \mathrm{C}$.

\subsubsection{LBG agar}

Composition $(\mathrm{g} / \mathrm{l})$ : tryptone -10 ; yeast extract $-5 ; \mathrm{NaCl}$ -10 ; glucose -10 ; agar $-15 ; \mathrm{pH}=7,5$. Sterilization -20 $\min$ at $121^{\circ} \mathrm{C}$.

\section{Methods of analysis}

\subsection{Determination of the antimicrobial activity of Lactobacillus acidophilus L12 against pathogenic microorganisms - by co-culturing}

To determine the antimicrobial activity of the studied strain against pathogenic bacteria, a $24 \mathrm{~h}$ culture of Lactobacillus acidophilus L12 (the concentration of viable cells being $10^{9} \mathrm{cfu} / \mathrm{ml}$ ) was used. $0.5 \mathrm{~mL}$ of the lactobacilli suspension was mixed with $0.5 \mathrm{~mL}$ of the pathogen suspension (the concentration of viable cells being $10^{9} \mathrm{cfu} / \mathrm{ml}$ ) and $9 \mathrm{~mL}$ of culture medium (MRS broth or LAPTg10 broth). For the Lactobacillus acidophilus L12 control as well as for the pathogen controls $9.5 \mathrm{~mL}$ of the respective culture medium was mixed with $0.5 \mathrm{~mL}$ of the lactobacilli suspension or the pathogen suspension, respectively. Co-cultivation of lactobacilli and pathogenic bacteria was performed under static conditions at $37^{\circ} \mathrm{C}$ for 60 to $72 \mathrm{~h}$, taking samples at $0,12,24,36,48,60$, and $72 \mathrm{~h}$ and monitoring the change in the titratable acidity and the concentration of viable cells of both the pathogen and Lactobacillus acidophilus L12 [7].

\subsection{Determination of the titratable acidity}

Torner's method was used to determine the acid-forming ability of lactic acid bacteria. One ${ }^{\circ} \mathrm{T}$ equals $1 \mathrm{~mL}$ of $0.1 \mathrm{~N} \mathrm{NaOH}$ used to neutralize an equivalent amount of organic acid contained in $100 \mathrm{~mL}$ of culture medium.

The method was based on titration of the sample with $0.1 \mathrm{~N} \mathrm{NaOH}$. For this purpose, $10 \mathrm{~mL}$ of each sample were mixed with $20 \mathrm{~mL}$ of distilled water. The mixture was titrated with $0.1 \mathrm{~N} \mathrm{NaOH}$ using phenolphthalein as an indicator until the appearance of a light pink color that persists for one minute [8].

\subsection{Determination of the number of viable cells of lactobacilli and pathogenic microorganisms}

Appropriate tenfold dilutions of each sample were prepared and used for spread-plating on LAPTg10-agar (for the enumeration of lactobacilli) and on LBG-agar (for the enumeration of pathogenic bacteria). The inoculated Petri dishes were cultured for 3 days at $37^{\circ} \mathrm{C}$ until the appearance of countable single colonies. The number of the colonies was used to estimate the number of viable cells in the original sample [7].

\subsection{Determination of kinetic parameters}

The classical (1) and modified models of the logistic curve (2) were used to model the growth kinetics. Since the amount of pathogens killed per time unit as a result of the antimicrobial metabolites released by the lactobacilli (lactic acid and other organic acids and bacteriocins) is proportional to the initial amount of living cells, an equation describing the kinetics of firstorder chemical reactions was used to describe the death kinetics (3). 


$$
\begin{aligned}
\frac{d X}{d \tau}=\mu X- & \beta X^{2} \\
& \Rightarrow \mu X-\frac{\mu}{X_{k}} X^{2} \\
& \Rightarrow \mu\left(1-\frac{X}{X_{K}}\right) X \\
\frac{d X}{d \tau}=(\mu X- & \left.\beta X^{2}\right)^{n} \\
& \Rightarrow\left(\mu X-\frac{\mu}{X_{k}} X^{2}\right)^{n} \\
& \Rightarrow \mu\left(1-\frac{X}{X_{K}}\right)^{n} X \\
\frac{d X}{d \tau}=-k X & \Rightarrow X=X_{0} e^{-k \tau}
\end{aligned}
$$

Where: $\mu$ is the maximum specific growth rate, $\mathrm{h}^{-1}$; $\mathrm{X}_{0}, \mathrm{X}$ and $\mathrm{X}_{\mathrm{k}}$ are the initial, current and final biomass concentrations, respectively, $\mathrm{cfu} / \mathrm{mL} ; \beta$ - coefficient of internal population competition, $\mathrm{cfu} / \mathrm{mL} . \mathrm{h} ; \mathrm{k}$ - death rate, $\mathrm{h}^{-1} ; \mathrm{n}-$ parameter, describing the influence of the composition of the medium and the metabolic products released by the studied microorganisms (lactobacilli and pathogens) on the cells and their growth; $\tau$ - time, $\mathrm{h}^{-1}$.

The differential equations were solved by the $4^{\text {th }}$ order Runge-Kutta method [9] in Excel. The general and discretized type of the equation are:

$$
\begin{gathered}
\frac{d y}{d x}=F(x, y) \\
\frac{y_{i+1}-y_{i}}{x_{i+1}-x_{i}}=\frac{y_{i+1}-y_{i}}{h}=F(x, y)
\end{gathered}
$$

Where $\mathrm{h}$ is step of the solution.

For a system of ordinary differential equations $(\mathrm{k}=1$, $\ldots, \mathrm{K}$ equations):

$$
\begin{aligned}
& \frac{d y_{1}}{d x_{1}}=F_{1}\left(x, y_{1}, y_{2}, \cdots \cdots \cdots, y_{k}\right) \\
& \frac{d y_{2}}{d x_{2}}=F_{2}\left(x, y_{1}, y_{2}, \cdots \cdots \cdots, y_{k}\right) \\
& \frac{d y_{k}}{d x_{k}}=F_{1}\left(x, y_{1}, y_{2}, \cdots \cdots \cdots, y_{k}\right)
\end{aligned}
$$

The algorithm for solving ordinary differential equations by the method of Runge-Kutta of the $4^{\text {th }}$ order, is the following:

$$
\begin{gathered}
y_{k, i+1}=y_{k, i}+\frac{1}{6}\left(k_{k, 1}+2 \cdot k_{k, 2}+2 \cdot k_{k, 3}+k_{k, 4}\right) \\
k_{k, 2}=h F_{k}\left(x_{i}+\frac{h}{2}, y_{k, i}+\frac{k_{k, 1}}{2}\right) \\
k_{k, 1}=h F_{k}\left(x_{i}, y_{1, i}, y_{2, i}, \cdots \cdots \cdots y_{k, i}\right) \\
k_{k, 3}=h F_{k}\left(x_{i}+\frac{h}{2}, y_{k, i}+\frac{k_{k, 2}}{2}\right) \\
k_{k, 4}=h F_{k}\left(x_{i}+h, y_{k, i}+k_{k, 3}\right)
\end{gathered}
$$

The Solver function in Excel was used to identify the parameters of the models. The model parameters were determined by minimizing the square of the difference between the experimental data and those obtained from the respective model.

\subsection{Processing the results}

Data from triplicate experiments were processed with MS Office Excel 2010 software products, using statistical functions to determine the standard deviation and the maximum estimation error at significance levels of $p<0.05$.

\section{Results and discussion}

Lactobacillus strains are increasingly included in the composition of probiotics and functional foods. Several Lactobacillus acidophilus strains are Generally Recognized as Safe by the FDA and benefit from a Qualified Presumption of Safety status in EU., Lb. acidophilus bacteria are thus included in a wide range of probiotic preparations and probiotic foods marketed. A study is necessary to determine the probiotic potential of Lactobacillus acidophilus L12.

The antimicrobial activity of the potentially probiotic Lactobacillus acidophilus L12 strain against Escherichia coli, Staphylococcus aureus and Salmonella sp. was examined in vitro through co-culturing with each of the 6 pathogenic bacterial strains tested for $72 \mathrm{~h}$, monitoring the changes in the number of viable cells of the probiotic strain and the pathogenic strains as well as the changes in the titratable acidity. All strains reached high number of viable cells after $72 \mathrm{~h}$ separate culturing (Fig. 1a, Fig. 2a, Fig. 3a, Fig. 4a, Fig. 5a, Fig. 6a). Lactobacillus acidophilus L12 always reached a high concentration of viable cells during its co-culturing with each of the test pathogenic strains, while the concentration of viable cells of the pathogenic strains was reduced in a strain-specific manner (Fig. 1a, Fig. 2a, Fig. 3a, Fig. 4a, Fig. 5a, Fig. 6a).

During the separate growth of Lactobacillus acidophilus L12 under static conditions for 12-24 h, the 
titratable acidity of the medium reached $90^{\circ} \mathrm{T}$ (Fig. 1b, Fig. 2b).

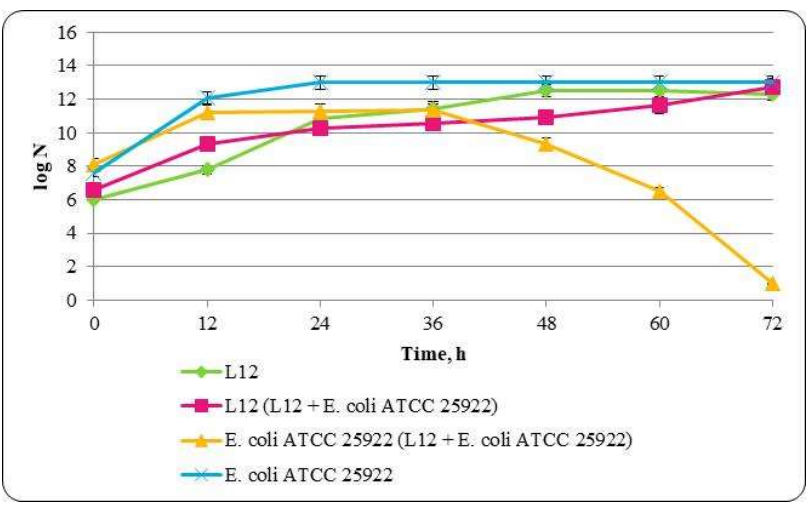

Fig. 1a. Monitoring of the number of viable cells of $L b$. acidophilus L12 and E. coli ATCC 25922 during separate culturing and co-culturing at $37 \pm 1^{\circ} \mathrm{C}$.

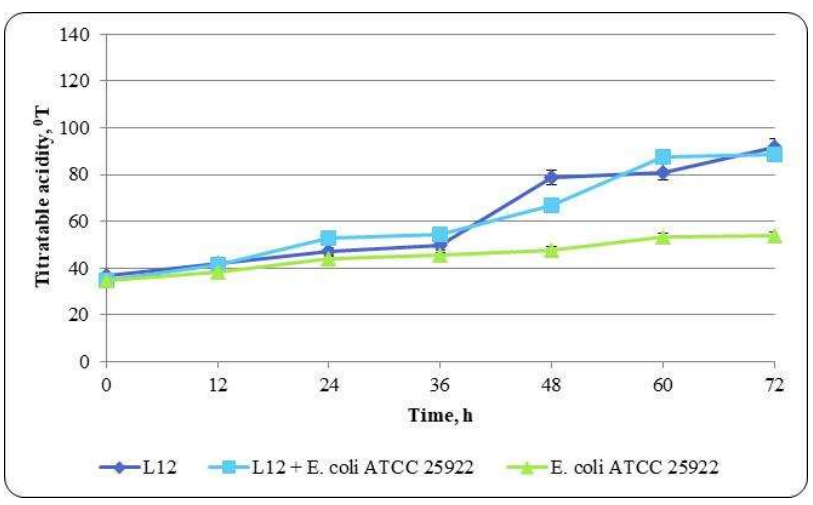

Fig. 1b. Monitoring of the titratable acidity of the medium during separate culturing and co-culturing of $L b$. acidophilus L12 and E. coli ATCC 25922 at $37 \pm 1{ }^{\circ} \mathrm{C}$.

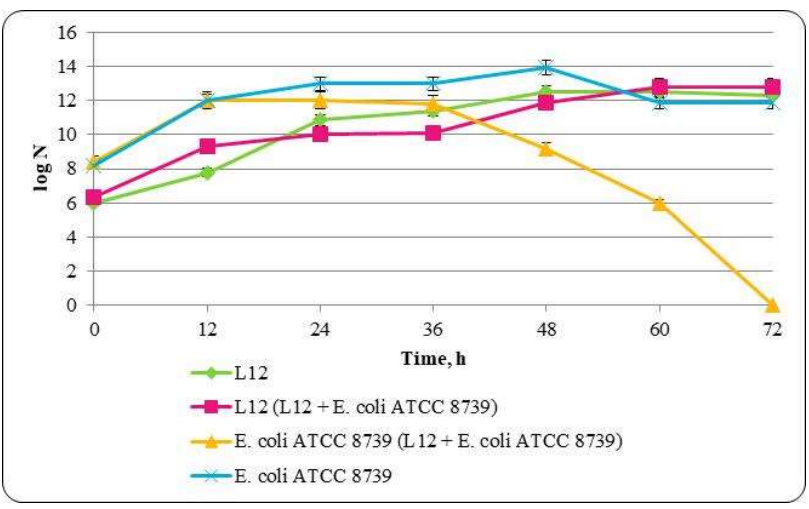

Fig. 2a. Changes in the number of viable cells of $L b$. acidophilus $\mathrm{L} 12$ and E. coli ATCC 8739 during separate culturing and co-culturing at $37 \pm 1^{\circ} \mathrm{C}$.

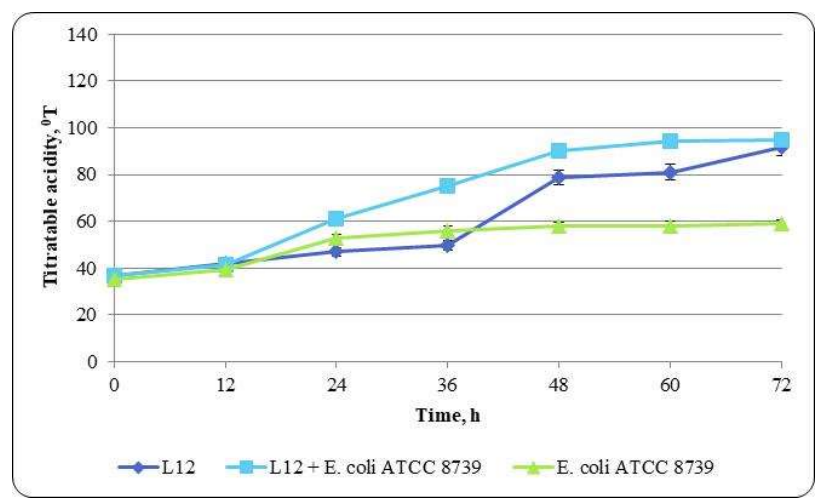

Fig. 2b. Changes in the titratable acidity of the medium during separate culturing and co-culturing of Lb. acidophilus L12 and E. coli ATCC 8739 at $37 \pm 1^{\circ} \mathrm{C}$.

In the co-culturing of Lactobacillus acidophilus L12 and Escherichia coli ATCC 25922 at $37 \pm 1{ }^{\circ} \mathrm{C}$ under static conditions, an increase in the concentration of viable cells of Escherichia coli ATCC 25922 was observed during the first $36 \mathrm{~h}$, followed by gradual decrease, reaching almost 0 after 72 h (Fig. 1a).

When Lactobacillus acidophilus L12 was co-cultured with Escherichia coli ATCC 8739 at $37 \pm 1^{\circ} \mathrm{C}$ under static conditions, there was an increase in the number of living cells of the pathogen during the first $36 \mathrm{~h}$. Then, a sharp decrease in the number of living cells of Escherichia coli ATCC 8739 began, and no viable cells of the pathogenic microorganism were identified after $72 \mathrm{~h}$ (Fig. 2a).

The established inhibition of the pathogens by the lactobacilli strain in the mixtures might be due to the increase in the titratable acidity due to the accumulation of lactic acid and other organic acids, as well as the production of peptide metabolites such as bacteriocins with antimicrobial action in the medium.

In a mixed population of Lactobacillus acidophilus L12 and Salmonella sp., the concentration of viable pathogen cells began to decrease after $36 \mathrm{~h}$ and after $72 \mathrm{~h}$ there were about $10^{3} \mathrm{cfu} / \mathrm{ml}$ living cells of Salmonella abony NTCC 6017. In the co-culturing of Lactobacillus acidophilus L12 and Salmonella enteritidis ATCC 13076 the reduction of viable pathogen cells began after $24 \mathrm{~h}$ and after $72 \mathrm{~h}$ no living pathogenic bacteria were detected, while for the same time interval the concentration of lactobacilli reached above $10^{12}$ cfu/mL (Fig. 3a, Fig. 4a).

When examining the antagonistic activity of Lactobacillus acidophilus L12 against Staphylococcus aureus ATCC 25293 and Staphylococcus aureus ATCC $6538 \mathrm{P}$, there was an increase in the concentration of viable cells of both pathogens during the first $24 \mathrm{~h}$, followed by a decrease and the number of living pathogens by the $72^{\text {nd }} \mathrm{h}$ was less than the detection threshold which was $10 \mathrm{cfu} / \mathrm{mL}$ (Fig. 5a, Fig. 6a). 


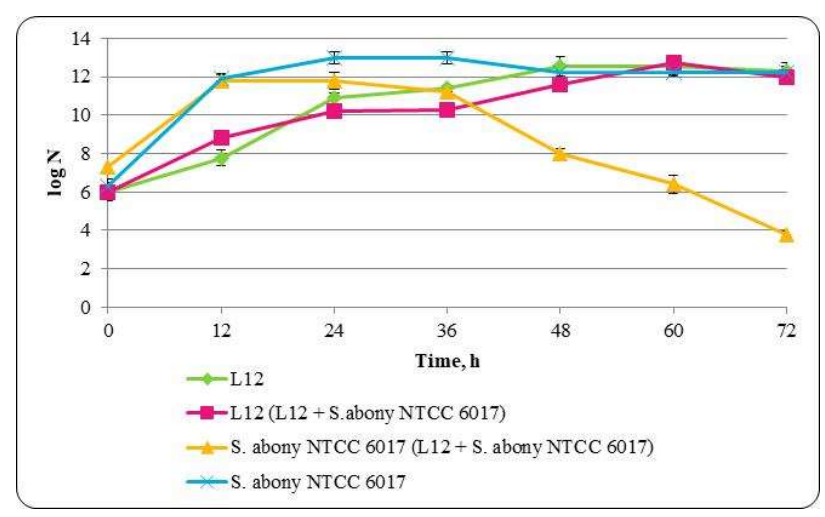

Fig. 3a. Changes in the number of viable cells of $L b$. acidophilus L12 and S. abony NTCC 6017 during separate culturing and co-culturing at $37 \pm 1{ }^{\circ} \mathrm{C}$.

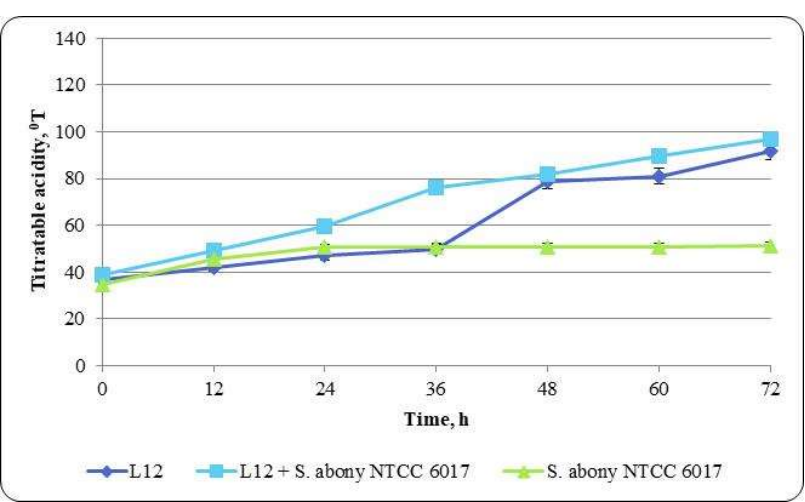

Fig. 3b. Changes in the titratable acidity of the medium during separate culturing and co-culturing of Lb. acidophilus L12 and S. abony NTCC 6017 at $37 \pm 1^{\circ} \mathrm{C}$.

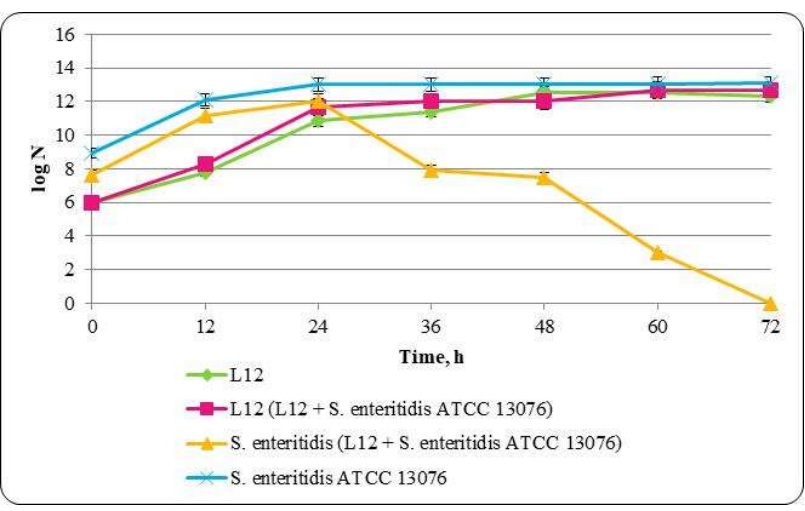

Fig. 4a. Changes in the number of viable cells of $L b$. acidophilus L12 and S. enteritidis ATCC 13076 during separate culturing and co-culturing at $37 \pm 1^{\circ} \mathrm{C}$.

As expected, while titratable acidity increased over time when Lactobacillus acidophilus L12, which is a lactic acid bacterium, was inoculated unlike when pathogenic bacteria were inoculated alone. (Fig. 1b, Fig. 2b, Fig. 3b, Fig. 4b, Fig. 5b, Fig. 6b).

Acidification of broth leads to a change in the conditions for the growth of the pathogenic bacteria.

The inhibition of their growth by the Lactobacillus plantarum strain was thus likely largely due to the reduced $\mathrm{pH}$ and to the formation and accumulation of lactic acid and other organic acids. However, it could also result from the synthesis of other antimicrobial metabolites by Lactobacillus acidophilus L12, such as bacteriocins.

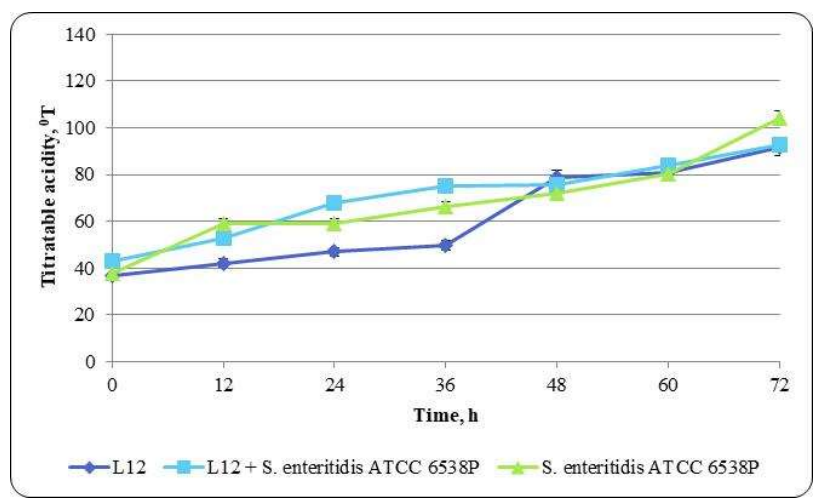

Fig. 4b. Changes in the titratable acidity of the medium during separate culturing and co-culturing of Lb. acidophilus L12 and S. enteritidis ATCC 13076 at $37 \pm 1^{\circ} \mathrm{C}$.

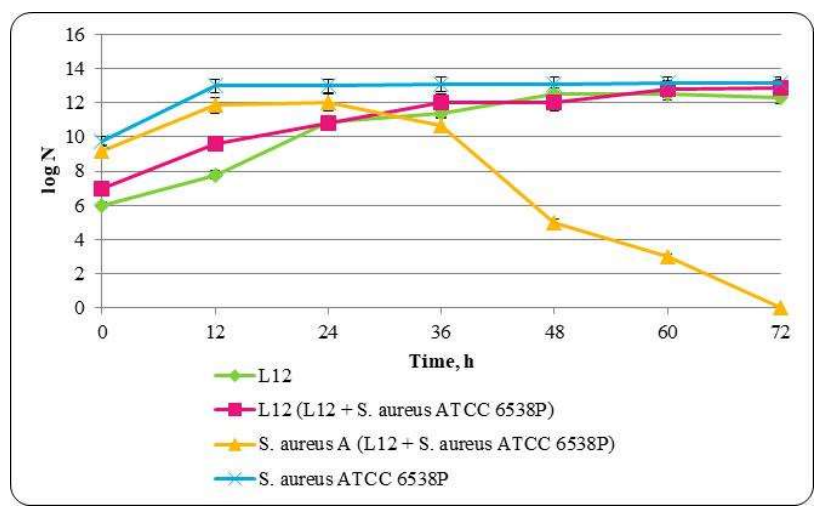

Fig. 5a. Changes in the number of viable cells of $L b$. acidophilus L12 and $S$. aureus ATCC 6538P during separate culturing and co-culturing at $37 \pm 1^{\circ} \mathrm{C}$.

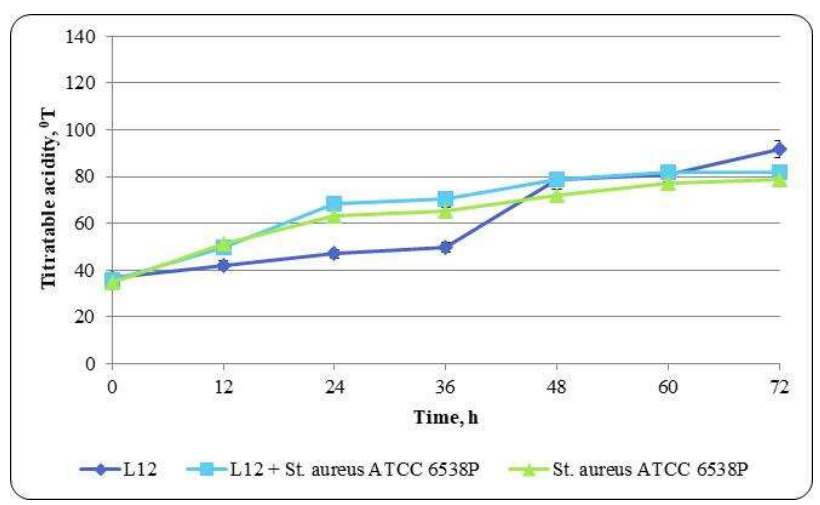

Fig. 5b. Changes in the titratable acidity of the medium during separate culturing and co-culturing of $\mathrm{Lb}$. acidophilus L12 and $S$. aureus ATCC $6538 \mathrm{P}$ at $37 \pm 1^{\circ} \mathrm{C}$.

In order to clarify the interaction of pathogens and lactobacilli in their co-cultivation, it is important to monitor the changes in their maximum specific growth rates.

An important kinetic parameter is the pathogen death rate and its reciprocal value, which shows the resistance of the pathogen to the created adverse conditions.

Table 1 shows the kinetic parameters for lactobacilli and pathogens in separate culturing and in co-culturing. 


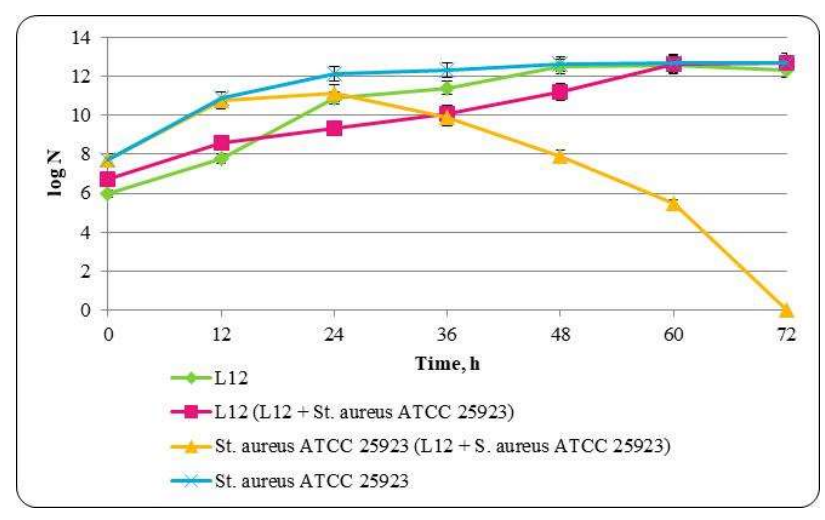

Fig. 6a. Changes in the number of viable cells of $L b$. acidophilus L12 and S. aureus ATCC 25293 during separate culturing and co-culturing at $37 \pm 1^{\circ} \mathrm{C}$.

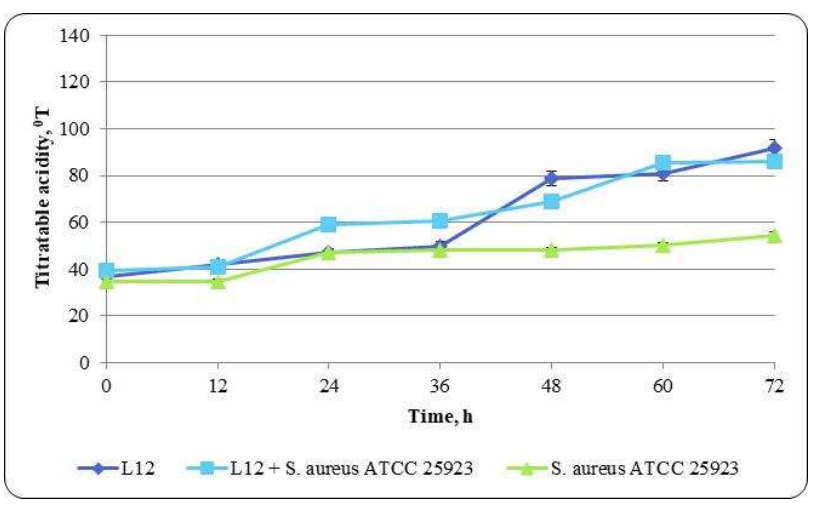

Fig. 6b. Changes in the titratable acidity of the medium during separate culturing and co-culturing of $L b$. acidophilus L12 and S. aureus ATCC 25293 at $37 \pm 1^{\circ} \mathrm{C}$.

In the co-culturing of Lactobacillus acidophilus L12 and the pathogens Staphylococcus abony NTCC 6017, S. enteritidis ATCC 13076, Staphylococcus aureus ATCC 6538P, Staphylococcus aureus ATCC 25293, Escherichia coli ATCC 25922 and Escherichia coli ATCC 8739, the maximum specific growth rate of Lactobacillus acidophilus L12 decreased, but yet it retained relatively high values. According to the two logistic models, it varied in the range from 0.026 to 0.038 $\mathrm{h}^{-1}$ (compared to its value in separate culturing that varied between $0.040^{-1}$ and $0.042 \mathrm{~h}^{-1}$ ). There was also an increase in the parameter $\mathbf{n}$, which ranged from 0.9917 to 1.1761 , which is a result of the competition of lactobacilli and pathogens for nutrients. In addition, the increase in the value of the parameter $\mathbf{n}$ shows certain influence of the metabolites released by the pathogens on the growth of Lb. acidophilus L12. Nevertheless, high values of the maximum concentration of active cells of Lactobacillus acidophilus L12, which would theoretically be reached in the mixed population, were observed. According to the models used, $X_{\mathrm{k}}$ had values close to the control (separate culturing of the strain) and varied in the range from 12.10 $\log \mathrm{N}$ to $13.03 \log \mathrm{N}$.

In the co-culturing of Staphylococcus aureus ATCC 25293 and S. aureus ATCC 6538P with Lactobacillus acidophilus L12, a reduction in the maximum specific growth rate of the pathogens was determined. According to the models used, $\mu$ decreased from $0.089 \mathrm{~h}^{-1}$ and 0.096 $\mathrm{h}^{-1}$ to $0.062 \mathrm{~h}^{-1}$ and $0.051 \mathrm{~h}^{-1}$ for Staphylococcus aureus ATCC 25293, while $\mu$ decreased from $0.085 \mathrm{~h}^{-1}$ and $0.099 \mathrm{~h}^{-1}$ to $0.051 \mathrm{~h}^{-1}$ and $0.070 \mathrm{~h}^{-1}$ for Staphylococcus aureus ATCC 6538P. With the two strains studied, the parameter $\mathbf{n}$ increased, having values above 1. This parameter was 1.0486 and 1.0265 for Staphylococcus aureus ATCC 25293 and Staphylococcus aureus ATCC $6538 \mathrm{P}$, respectively. This indicated that the pathogen growth was influenced by the presence of the lactobacilli and their metabolites with antimicrobial activity. This fact was confirmed by the reduction of the maximum final concentration of active cells of the studied pathogen, which would theoretically be reached in the mixed population. $\mathrm{X}_{\mathrm{k}}$ for Staphylococcus aureus ATCC 25293 was $10.30 \log \mathrm{N}$ and $10.96 \log \mathrm{N}$, depending on the model, while $\mathrm{X}_{\mathrm{k}}$ for Staphylococcus aureus ATCC 6538P was $12.48 \log \mathrm{N}$ and $12.80 \log \mathrm{N}$. Relatively high and comparable values of the death rate constant were observed for the two $S$. aureus strains $-0.615 \mathrm{~h}^{-1}$ and $0.608 \mathrm{~h}^{-1}$ for S. aureus ATCC 25293 and Staphylococcus aureus ATCC 6538P, respectively.

In the co-cultivation of Staphylococcus abony NTCC 6017 and $L b$. acidophilus L12, a reduction in the maximum specific growth rate of the studied pathogen was observed. According to the two logistics models for Staphylococcus abony NTCC $6017 \mu$ was $0.068 \mathrm{~h}^{-1}$ and $0.075 \mathrm{~h}^{-1}$. According to the modified logistics model, the reduction in the maximum specific growth rate of the pathogen was significant, compared to the control, where $\mu$ had a $0.278 \mathrm{~h}^{-1}$ value. With Staphylococcus abony NTCC 6017, a certain increase in the parameter $\mathbf{n}$ was observed. It was 0.9842 (compared to the control 0.8909). This indicated that the pathogen would resist the conditions created by the presence of the lactobacilli and their metabolites longer. For Staphylococcus abony NTCC 6017 , the two logistic models predicted by almost one logarithmic unit a lower value of $\mathrm{X}_{\mathrm{k}}$, and the value according to the models was $10.83 \log \mathrm{N}$ and $10.91 \log$ $\mathrm{N}$ (compared to the control, where $\mathrm{X}_{\mathrm{k}}$ was $11.57 \log \mathrm{N}$ ). This strain has the lowest value of the death rate compared to all other pathogens studied. For Staphylococcus abony NTCC 6017 it was $0.322 \mathrm{~h}^{-1}$.

A reduction in the maximum specific growth rate by almost 50\% for Staphylococcus enteritidis ATCC 13076 was observed.

The $\mu$ values for this strain were $0.034 \mathrm{~h}^{-1}$ and $0.046 \mathrm{~h}^{-1}$, compared to the control $\left(0.065 \mathrm{~h}^{-1}\right.$ and $\left.0.077 \mathrm{~h}^{-1}\right)$.

The parameter $\mathbf{n}$ increased for Staphylococcus enteritidis ATCC 13076, and its value was 1.0248, which in turn indicated that the strain was affected by the presence of the lactobacilli and their metabolites. In the co-cultivation of Staphylococcus enteritidis ATCC 13076 and Lactobacillus acidophilus L12, a significant decrease in the maximum concentration of active cells of the pathogen, which would theoretically be reached in the mixed population - $11.64 \log \mathrm{N}$ and $11.63 \log \mathrm{N}$ (compared to the control -14.37 $\log \mathrm{N}$ and $14.29 \log \mathrm{N}$ ), was observed. This pathogen had a relatively high death rate $-0.535 \mathrm{~h}^{-1}$. 
Table 1. Kinetic parameters.

\begin{tabular}{|c|c|c|c|c|c|c|c|c|}
\hline \multirow{3}{*}{ Strain/Mixture } & \multicolumn{8}{|c|}{ Kinetic parameters } \\
\hline & \multicolumn{3}{|c|}{ Model 1} & \multicolumn{4}{|c|}{ Model 2} & \multirow{2}{*}{\begin{tabular}{|c} 
Model 3 \\
$\begin{array}{c}\mathbf{k}, \\
\mathbf{h}^{-1}\end{array}$
\end{tabular}} \\
\hline & $\begin{array}{c}\mu, \\
\mathbf{h}^{-1}\end{array}$ & $\begin{array}{c}\beta, \\
\text { cfu/mL.h }\end{array}$ & $\begin{array}{c}X_{K} \\
\text { cfu/mL }\end{array}$ & $\begin{array}{c}\mu \\
\mathbf{h}^{-1}\end{array}$ & $\begin{array}{c}\beta, \\
\text { cfu/mL.h }\end{array}$ & $\begin{array}{c}X_{K} \\
\text { cfu/mL }\end{array}$ & n & \\
\hline Lb. acidophilus L12 к & 0.040 & 0.0030 & 13.07 & 0.042 & 0.0032 & 13.14 & 0.8990 & - \\
\hline S. abony NTCC 6017 к & 0.077 & 0.0066 & 11.57 & 0.278 & 0.0240 & 11.57 & 0.9419 & - \\
\hline S. enteritidis АТСС 13076 к & 0.065 & 0.0045 & 14.37 & 0.077 & 0.0054 & 14.29 & 0.8909 & - \\
\hline S. aureus АТCC 25923 к & 0.089 & 0.0065 & 13.68 & 0.096 & 0.0064 & 14.96 & 0.9064 & - \\
\hline S. aureus АТСС 6538P к & 0.085 & 0.0063 & 13.46 & 0.099 & 0.0071 & 13.96 & 0.9641 & - \\
\hline E. coli АТСС 25922 к & 0.099 & 0.0074 & 13.33 & 0.086 & 0.0064 & 13.35 & 0.9017 & - \\
\hline E.coli АТCC 8739 к & 0.096 & 0.0070 & 13.85 & 0.097 & 0.0073 & 13.35 & 0.9010 & - \\
\hline $\begin{array}{l}\text { Lb. acidophilus L12 } \\
\text { (Lb. acidophilus L12 + } \\
\text { S. abony NTCC 6017) }\end{array}$ & 0.029 & 0.0024 & 12.49 & 0.033 & 0.0025 & 13.03 & 1.0988 & - \\
\hline $\begin{array}{l}\text { Lb. acidophilus L12 } \\
\text { (Lb. acidophilus } \mathrm{L} 12+ \\
\text { S. enteritidis ATCC 13076) }\end{array}$ & 0.036 & 0.0028 & 12.89 & 0.034 & 0.0026 & 12.80 & 0.9917 & - \\
\hline $\begin{array}{l}\text { Lb. acidophilus L12 (Lb. } \\
\text { acidophilus } \mathrm{L} 12+ \\
\text { S. aureus ATCC 6538P) } \\
\end{array}$ & 0.032 & 0.0020 & 12.82 & 0.038 & 0.0030 & 12,65 & 0.9940 & - \\
\hline $\begin{array}{l}\text { Lb. acidophilus L12 } \\
\text { (Lb. acidophilus } \mathrm{L} 12+ \\
\text { S. aureus ATCC 25923) }\end{array}$ & 0.027 & 0.0021 & 12.44 & 0.036 & 0.0028 & 12.68 & 1.1761 & - \\
\hline $\begin{array}{l}\text { Lb. acidophilus L12 } \\
\text { (Lb. acidophilus } \mathrm{L12}+ \\
\text { E. coli ATCC 25922) }\end{array}$ & 0.026 & 0.0021 & 12.10 & 0.027 & 0.0022 & 12.44 & 1.1350 & - \\
\hline $\begin{array}{l}\text { Lb. acidophilus L12 } \\
\text { (Lb. acidophilus L12 + } \\
\text { E. coli ATCC 8739) }\end{array}$ & 0.025 & 0.0020 & 12.89 & 0.038 & 0.0030 & 12.83 & 1.0996 & - \\
\hline $\begin{array}{l}\text { S. abony NTCC } 6017 \\
\text { (Lb. acidophilus L12 }+ \text { S. } \\
\text { abony NTCC 6017) }\end{array}$ & 0.068 & 0.0063 & 10.83 & 0.075 & 0.0069 & 10.91 & 0.9842 & 0.322 \\
\hline $\begin{array}{l}\text { S. enteritidis ATCC } 13076 \\
\text { (Lb. acidophilus } \mathrm{L} 12+S . \\
\text { enteritidis ATCC 13076) }\end{array}$ & 0.034 & 0.0029 & 11.64 & 0.046 & 0.0040 & 11.63 & 1.0248 & 0.535 \\
\hline $\begin{array}{l}\text { S. aureus ATCC } 25923 \\
\text { (Lb. acidophilus } \mathrm{L} 12+S \text {. } \\
\text { aureus ATCC 25923) }\end{array}$ & 0.062 & 0.0060 & 10.36 & 0.051 & 0.0046 & 10.96 & 1.0486 & 0.615 \\
\hline $\begin{array}{l}\text { S. aureus ATCC 6538P } \\
\text { (Lb. acidophilus } \mathrm{L12}+\text { S. } \\
\text { aureus ATCC 6538P) }\end{array}$ & 0.058 & 0.0047 & 12.48 & 0.070 & 0.0055 & 12.80 & 1.0265 & 0.608 \\
\hline $\begin{array}{l}\text { E. coli ATCC } 25922 \\
\text { (Lb. acidophilus } \mathrm{L12}+\text { E. coli } \\
\text { ATCC 25922) }\end{array}$ & 0.071 & 0.0068 & 10.47 & 0.078 & 0.0075 & 10.52 & 1.0121 & 0.652 \\
\hline $\begin{array}{l}\text { E. coli ATCC } 8739 \\
\text { (Lb. acidophilus } \mathrm{L} 12+ \\
\text { E. coli } \text { ATCC 8739) }\end{array}$ & 0.031 & 0.0026 & 12.17 & 0.054 & 0.0045 & 12.18 & 1.0860 & 0.741 \\
\hline
\end{tabular}


In the co-culturing of Escherichia coli ATCC 25922 or Escherichia coli ATCC 8739 and Lactobacillus acidophilus L12, a reduction in the maximum specific growth rate was determined. The $\mu$ value for Escherichia coli ATCC 25922 was $0.071 \mathrm{~h}^{-1}$ and $0.078 \mathrm{~h}^{-1}$ (compared to the control for this strain in which $\mu$ was $0.099 \mathrm{~h}^{-1}$ and $\left.0.086 \mathrm{~h}^{-1}\right)$. The parameter $\mathbf{n}$ for this strain was 1.0121 (compared to the control, in which $\mathbf{n}$ was 0.9017 ), which showed that the growth of Escherichia coli ATCC 25922 was influenced by the presence of the lactobacilli and their metabolites with antimicrobial action. This was confirmed by the lower value of the maximum final concentration in the mixed population, which would theoretically reach $10.47 \log \mathrm{N}$ and $10.52 \log \mathrm{N}$. With this strain there was a relatively high death rate $-0.652 \mathrm{~h}^{-1}$.

A reduction in the maximum specific pathogen growth rate was also observed in the mixed population of Escherichia coli ATCC 8739 and Lactobacillus acidophilus L12. The $\mu$ value for Escherichia coli ATCC 8739 was $0.031 \mathrm{~h}^{-1}$ and $0.054 \mathrm{~h}^{-1}$.

The maximum final biomass concentration of Escherichia coli ATCC 8739 that would theoretically be reached in the mixed population, calculated according to the two models, was $12.17 \log \mathrm{N}$ and $12.18 \log \mathrm{N}$, which was almost one logarithmic unit lower than that of the control $(13.33 \log \mathrm{N}$ and $13.35 \log \mathrm{N})$. The death rate constant for Escherichia coli ATCC 8739 was $0.741 \mathrm{~h}^{-1}$.

The obtained results regarding the antimicrobial activity of the newly isolated strain with probiotic potential Lactobacillus acidophilus L12 against pathogenic microorganisms unequivocally showed that the strain demonstrated high inhibitory activity and a high degree of reduction of the viable cells of the studied pathogens. This is promising for the selection for inclusion in the composition of probiotics and functional foods.

\section{Conclusion}

Lactic acid bacteria and pathogenic microorganisms accumulate high concentrations of viable cells when cultured alone at a temperature of $37 \pm 1^{\circ} \mathrm{C}$. Lactobacillus acidophilus L12 demonstrated the strongest inhibitory activity against the two Staphylococcus aureus strains. Lactobacillus acidophilus L12 exhibited weaker inhibitory activity against the two Escherichia coli strains. Lactobacillus acidophilus L12 exhibited the weakest inhibitory activity against the two Salmonella sp. strains. The obtained results show the strong antagonistic activity of the potentially probiotic strain Lactobacillus acidophilus L12, thus making it a promising candidate for inclusion in the composition of probiotic preparations and functional probiotic foods.

Acknowledgements: The research in the present study was funded by project Programme „Healthy Foods for a Strong BioEconomy and Quality of Life" approved by DCM № 577/17.08.2018, Bulgarian Ministry of Education and Science and Bulgarian National Fund "Scientific Research" under the project КП-06-Rila/2 from 20.12.2018 "Bio-prEservation by the SynergistiC Action of Probiotics and plant Extracts (ESCAPE)".

\section{References}

1. G. Rajivgandhi, R.T.V. Vimala, G. Ramachandran, N. Manoharan. Advances in Probiotics: Microorganisms in Food and Health (Academic Press, Cambridge, MA, 2021).

2. F. Canon, T. Nidelet, E. Guédon, A. Thierry, V. Gagnaire. Front Microbiol. 11, 2088 (2020)

3. M. Pihurov, B. Păcularu-Burada, M. Cotârleț, M.A. Vasile, G.E. Bahrim. Microorg., 9, 2184 (2021)

4. C.H.J. Lin, D.C. Savage. FEMS Microbiol. Lett. 24, 67 (1984)

5. M. P. Mokoena. Molecules. 22, 1255 (2017)

6. H. W. Tang, P. Phapugrangkul, H.M. Fauzi, J.S. Tan, Int. J. Pept. Res. Ther. 28, 14 (2022)

7. R. Denkova, S. Ilieva, D. Nikolova, Y. Evstatieva, Z. Denkova, M. Yordanova, V. Yanakieva. Bulg. J. Agric. Sci. 2, 108-111 (2013)

8. G. D. Sadler, P. A. Murphy. Food Analysis (Springer Nature Switzerland AG, Ney York, 2010)

9. J.C. Butcher. Appl. Num. Math. 20, 247-260 (1996) 